\title{
Global Year Against Musculoskeletal Pain
}

\author{
Kenneth D Craig PhD
}

$\mathrm{T}$ he intense focus on specific challenges in understanding and controlling pain brought by the International Association for the Study of Pain program of Global Years Against Pain continues in the current Global Year Against Musculoskeletal Pain. The theme "When Moving Hurts" captures the miseries that people confront when mobility is diminished by acute and chronic pain.

In previous years, there has been a focus on the "Right to Pain Relief", "Pain in Children", "Pain in Older Persons", "Pain in Women" and "Cancer Pain". Pain Research Eु Management has taken pleasure in providing a vehicle whereby the

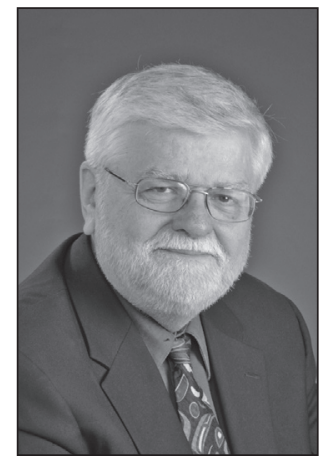

Dr Kenneth D Craig difficult to secure excellent papers exploring different facets of understanding and managing the different challenges of pain.

The present issue of Pain Research 8 Management features a comprehensive series of articles focusing on an evidence-based approach to whiplash injuries. All musculoskeletal disorders can pose serious challenges of pain and disability, with whiplashassociated disorders being one of the most serious public health problems. As this series of papers indicates, we are slowly making headway in understanding causes, assessment, treatment and intervention; however, much remains to be achieved in mastering the disabling pain resulting from musculoCanadian Pain Society joins the international movement represented by other International Association for the Study of Pain Chapters and Federations in combatting some of the most debilitating and refractory problems. Focusing on skeletal disorders. specific challenges seems to energize the research and practitioner community. In successive years, it has not been
Kenneth D Craig PhD

Editor-in-Chief

Pain Research 83 Management

Correspondence: Dr Kenneth D Craig, University of British Columbia, 2136 West Mall, Vancouver, British Columbia V6T 124.

Telephone 604-822-3948, fax 604-822-6923, e-mail kcraig@psych.ubc.ca 


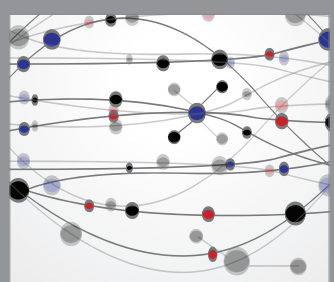

The Scientific World Journal
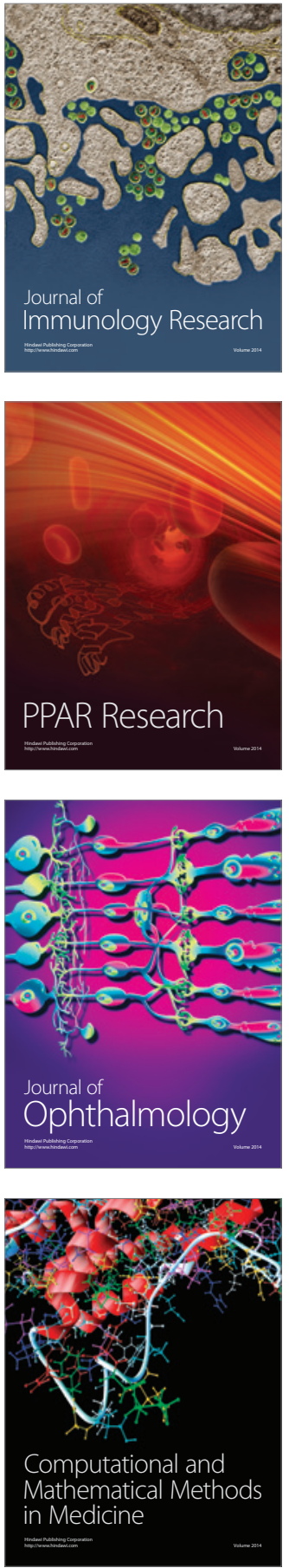

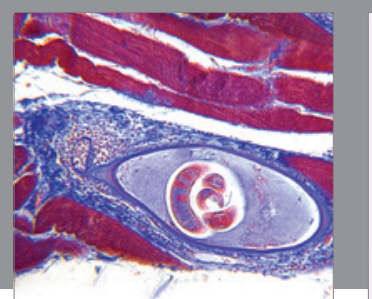

Gastroenterology Research and Practice

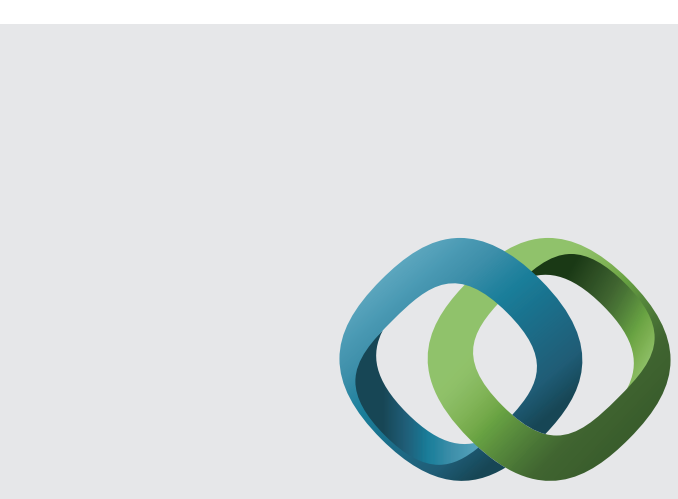

\section{Hindawi}

Submit your manuscripts at

http://www.hindawi.com
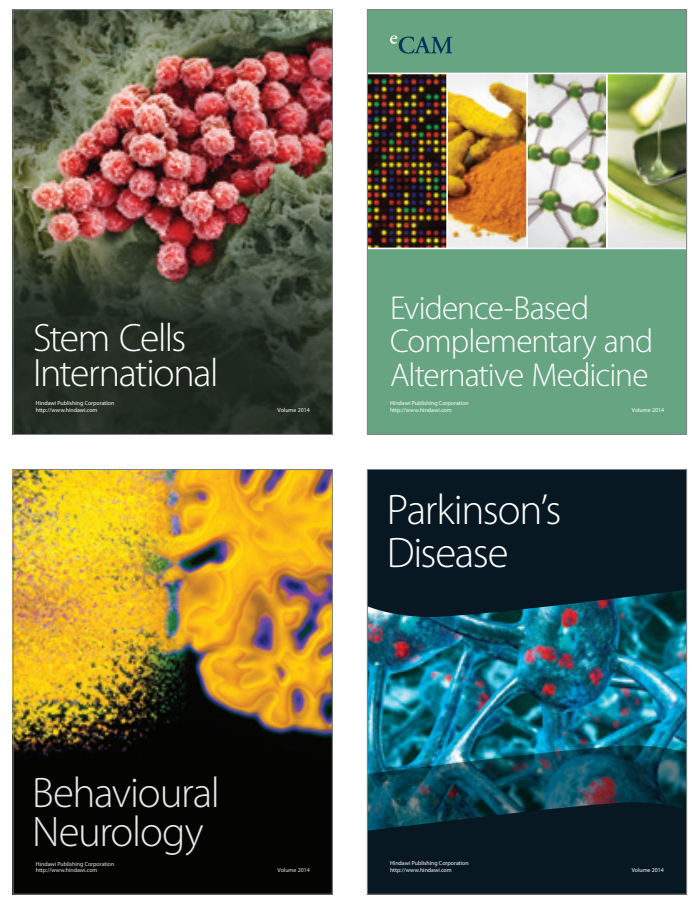
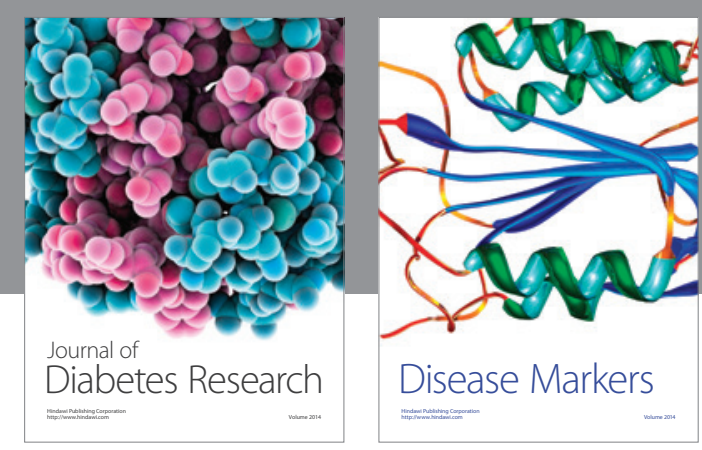

Disease Markers
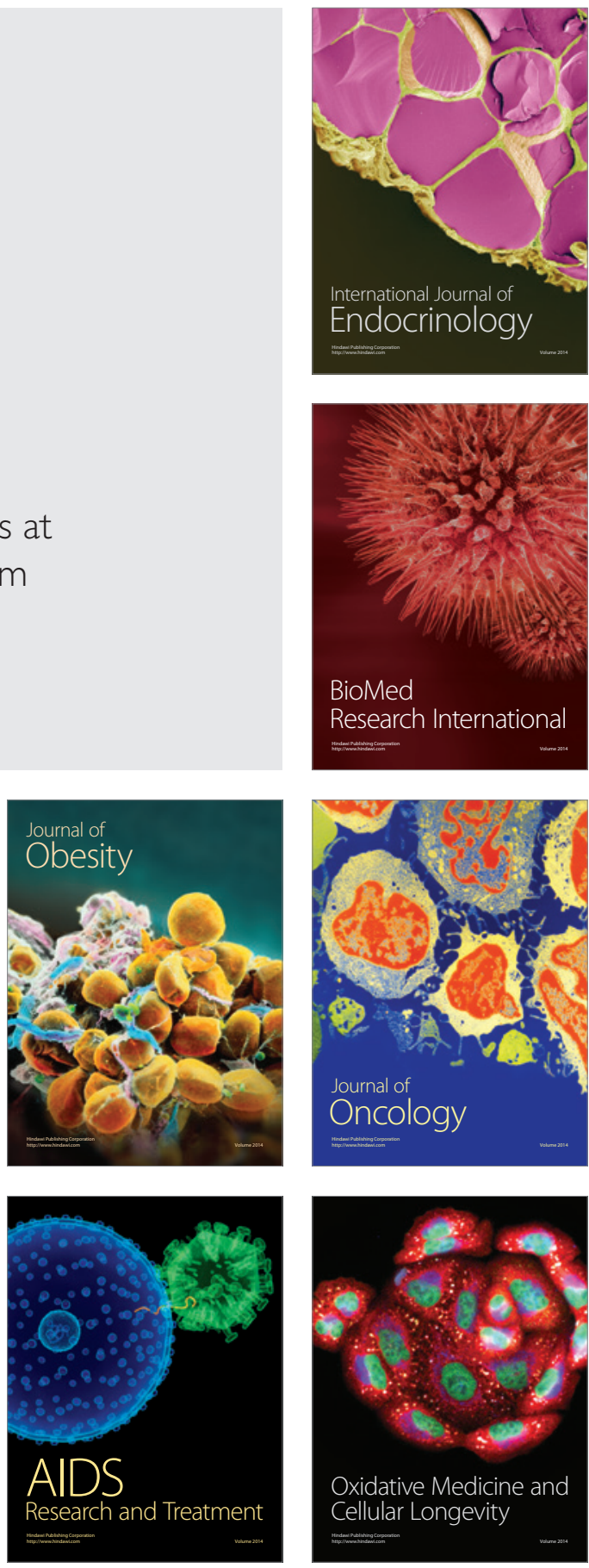